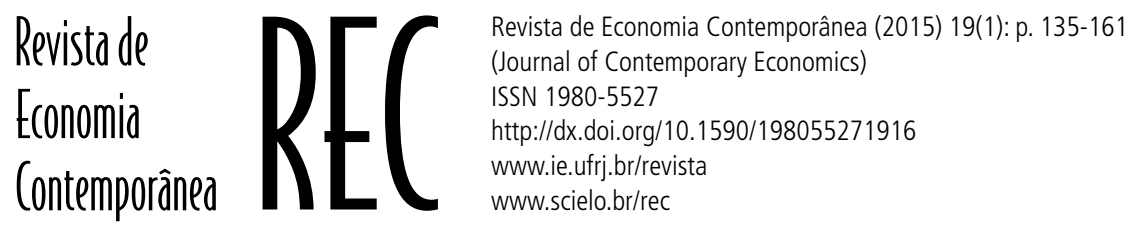

\title{
COMÉRCIO INTERNACIONAL, ALOCAÇÃO DO TRABALHO E A QUESTÃO DA DESINDUSTRIALIZAÇÃO NO BRASIL: UMA ABORDAGEM UTILIZANDO EQUILÍBRIO GERAL COMPUTÁVEL
}

\author{
Flávio Tosi Feijó ${ }^{a}$ \\ Camila Steffens ${ }^{b}$

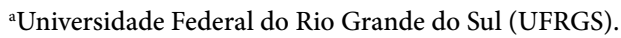 \\ ${ }^{\mathrm{b} U F R G S .}$ \\ Artigo recebido em 26/12/2013 e aceito em 26/01/2015.
}

\begin{abstract}
RESUMO: O presente artigo objetiva avaliar os impactos na alocação do emprego formal do fator trabalho no Brasil e verificar evidências de desindustrialização, mediante a simulação de cenários de aprofundamento do comércio internacional. O instrumento utilizado para as simulações é o modelo de Equilíbrio Geral Computável GTAP (Global Trade Analysis Project). Os resultados obtidos, combinados com os dados da RAIS (Relatório Anual de Informações Sociais), indicaram evidências de desindustrialização, devido à queda do emprego na indústria de transformação brasileira, principalmente no nível de qualificação média. Acordos preferenciais de comércio com a Ásia e com a União Europeia seriam os que mais contribuiriam para a referida redução. Entretanto, haveria ganhos de bem-estar em decorrência da melhor alocação dos recursos produtivos e dos termos de troca.
\end{abstract}

PALAVRAS-CHAVE: desindustrialização; comércio internacional; Brasil; GTAP.

CLASSIFICAÇÃO JEL: F14; F16; O14.

\footnotetext{
Correspondência para: Flavio Tosi Feijó.

Email: feijotosiflavio@gmail.com e flavio.tosi@ufrgs.br.
} 


\title{
INTERNATIONAL TRADE, LABOR ALLOCATION AND THE ISSUE OF DEINDUSTRIALIZATION IN BRAZIL: AN APPROACH USING COMPUTABLE GENERAL EQUILIBRIUM
}

\begin{abstract}
The present study aims to evaluate the impacts on the allocation of formal employment of labor factor in Brazil and verify evidence of deindustrialization, when a deepening of international trade occurs. The instrument used for the simulations of the scenarios, the GTAP (Global Trade Analysis Project), is a model of Computable General Equilibrium (CGE). The results, combined with data from RAIS (Annual Report of Social Information), indicated evidences of deindustrialization, due to the fall of employment in the Brazilian manufacturing industry, mainly in the average level of qualification. Preferential trade agreements with Asia and with the European Union would be the ones that would most contribute to it. However, there would be gains in welfare due to better allocation of productive resources and terms of trade.
\end{abstract}

KEYWORDS: deindustrialization; international trade; Brazil; GTAP. 


\section{INTRODUÇÃO}

Concomitantemente ao processo de abertura comercial no Brasil, que se iniciou no final dos anos 1980, tem-se verificado uma diminuição da participação do emprego da indústria de transformação no emprego total, ou seja, um processo de desindustrialização (Marquetti, 2002; Bonelli, 2005; Feijó, Carvalho e Almeida, 2005). Costuma-se mencionar, na literatura pertinente, causas internas e externas para esse processo. As causas internas estariam associadas à redução da elasticidade-renda na demanda por produtos industrializados e ao maior crescimento da produtividade na indústria, em relação ao setor de serviços. As causas externas, ao grau de integração econômica e produtiva dos países inseridos no processo de globalização e à abundância de recursos naturais que, devido à apreciação cambial, pode gerar um fenômeno conhecido como "Doença Holandesa” (Palma, 2005; Rowthorn e Ramaswamy, 1999, apud Oreiro e Feijó, 2010).

O presente estudo tem como foco as causas externas da desindustrialização, especificamente o grau de integração econômica e produtiva proporcionado pelo comércio internacional. A contribuição deste estudo para a discussão sobre a desindustrialização no Brasil consiste em identificar a influência da intensificação do comércio internacional neste processo, o que foi pouco tratado pela literatura pertinente. $\mathrm{O}$ padrão de especialização proveniente do aprofundamento do comércio internacional, através de uma maior abertura comercial global ou da formação de acordos preferenciais de comércio, teria qual efeito sobre a alocação do trabalho formal no Brasil? Essa especialização seria poupadora de que tipo de trabalho: qualificado ou não qualificado? Essas são as questões que serão exploradas neste artigo, as quais são de extrema relevância para a identificação dos setores mais vulneráveis ao processo de liberalização comercial.

O objetivo do presente estudo é o de contribuir, em um sentido teórico, para o debate da desindustrialização, verificando qual padrão de especialização do trabalho pode surgir no Brasil em função de um aprofundamento da liberalização comercial com o mundo. A intensificação comercial será analisada em cenários de livre comércio global e de acordos comerciais bilaterais. Esses cenários, embora possam parecer pouco prováveis do ponto de vista de exequibilidade, possibilitam a constatação de evidências na alocação do trabalho no longo prazo, em uma tendência liberalizante do comércio mundial. Nesse sentido, este artigo visa a simular tal padrão de especialização através da eliminação de tarifas de importação e de subsídios à exportação, tanto em nível global quanto através de acordos preferenciais de comércio, bem como a verificar a nova alocação do emprego em seus diversos níveis de escolaridade (proxy para a qualificação do trabalho). A relevância disso está em analisar o trabalho não apenas como um fator homogêneo, mas como fatores de produção diversos de acordo com a qualificação. 
Para as simulações, utilizou-se um modelo de Equilíbrio Geral Computável (EGC), denominado Global Trade Analysis Project (GTAP), combinado com os dados do Relatório Anual de Informações Sociais (RAIS), dos quais foram obtidos os níveis de escolaridade dos trabalhadores empregados nos setores classificados na Classificação Nacional de Atividades Econômicas (CNAE 2.0). A utilização de modelos de EGC para fazer as simulações permite contemplar uma série de importantes interações entre diferentes setores e países/regiões.

Portanto, no contexto deste estudo, isso permite que se constate ex-ante quais setores produtivos seriam mais estimulados/desestimulados com a eliminação de barreiras tarifárias ao comércio internacional, verificando-se o impacto na demanda por trabalho nesses setores. Dessa forma, será possível identificar, ou não, indícios ex-ante de desindustrialização relacionados ao aprofundamento do livre comércio. A eliminação de tais barreiras permite evidenciar o potencial de competitividade dos distintos setores, o que, por sua vez, pode caracterizar uma nova "divisão do trabalho" decorrente do livre comércio. $\mathrm{Na}$ seção 2, será feita uma breve revisão de literatura, que embasará teoricamente as análises dos resultados, as quais constam na seção 4 . A seção 3 apresenta a metodologia utilizada para alcançar os objetivos traçados.

\section{REVISÃO DE LITERATURA}

Este estudo baseia-se no modelo de comércio internacional de Heckscher-Ohlin, considerando a liberalização comercial como uma aproximação à intensificação comercial. Tendo em conta a impraticabilidade de um livre comércio internacional ideal, a análise abrange também simulações de acordos preferenciais de comércio, com vistas a verificar a possibilidade de cenários mais realistas. Dessa forma, visa-se a analisar a alocação do emprego formal nesses dois cenários à luz do modelo supracitado. Nesta seção, portanto, será apresentada uma revisão de literatura dos tópicos norteadores do estudo.

\subsection{PADRÃO DE ESPECIALIZAÇÃO E A DEMANDA POR TRABALHO}

O referencial teórico para a análise da especialização comercial e produtiva utilizado neste trabalho é o modelo de Heckscher-Ohlin, cujo principal insight é o de que as diferentes dotações de fatores de produção definem o padrão do comércio internacional. Esse modelo considera dois países, dois produtos e dois fatores de produção (capital e trabalho), sendo que o padrão de especialização produtivo depende da intensi- 
dade de fatores utilizados em cada produto (a tecnologia de produção) e do fator relativamente abundante domesticamente. Assim, quando não há barreiras ao livre comércio, cada país especializa-se na produção que utiliza mais intensamente o seu recurso abundante, ou seja, no produto em que possui vantagem comparativa. Com isso, os países exportam bens que usam intensivamente os fatores de produção disponíveis em abundância. Da mesma forma, importam bens cuja produção use intensivamente fatores que sejam relativamente escassos internamente.

Embora o modelo de Heckscher-Ohlin considere apenas trabalho e capital como fatores de produção, podemos adaptá-lo para uma realidade que supra os objetivos deste artigo. Para exemplificar, considere um simples caso: dois países (um desenvolvido e outro em desenvolvimento), dois fatores de produção (trabalho qualificado e não qualificado), dois bens comercializáveis (máquinas e vestuário). Se o país desenvolvido possui dotação relativamente elevada de trabalho qualificado, isso lhe dará uma vantagem comparativa na fabricação de máquinas (trabalho qualificadointensivo), enquanto o país em desenvolvimento terá vantagem comparativa na produção de vestuário, o que requer trabalho não qualificado, pois se assume que esse seja seu fator abundante. Tendo em vista que o trabalho qualificado é um recurso escasso na maioria dos países em desenvolvimento, a abertura comercial com países mais desenvolvidos aumentaria a produção intensiva em trabalho não qualificado e, como resultado, a demanda por esse fator. Consequentemente, o preço dos bens intensivos nesse tipo de trabalho também aumentaria (Giovannetti e MenezesFilho, 2006).

No modelo supracitado, o comércio e os salários são relacionados unicamente pelas variações de preços dos produtos. Por exemplo, na ausência de choques tecnológicos, se algum fato externo reduzir o preço ao produtor do vestuário, relativamente ao preço das máquinas, o salário do trabalho não qualificado reduzirá com relação ao salário do trabalho qualificado. Essa ligação é conhecida como teorema Stolper-Samuelson, que assume que existe uma relação fixa entre os preços dos bens e a remuneração dos fatores de produção (Wood, 1995).

Ainda, com base no modelo de Heckscher-Ohlin, dadas a tecnologia e as preferências, existem duas possibilidades da existência de fatos externos que alteram os preços relativos dos bens: barreiras ao comércio e alterações nas ofertas relativas de trabalho qualificado e não qualificado. As barreiras ao comércio (tarifas e subsídios), objeto dos choques que serão implementados neste trabalho, consistem em um dos fatores que possibilitam a prática de preços diferentes do mesmo bem em dois países, limitando dessa forma o comércio e, por conseguinte, a especialização dos países na produção dos bens nos quais possuem vantagem comparativa. Com isso, pode ocorrer perda de bem-estar, pois os países deixam de importar, por preços mais baixos, produtos nos 
quais não possuem muita eficiência produtiva, utilizando, ainda, seus recursos na produção destes, em detrimento dos bens nos quais possuem maior vantagem comparativa.

\subsection{ACORDOS PREFERENCIAIS DE COMÉRCIO}

Embora o modelo de Heckscher-Ohlin consista em uma base teórica de liberalização comercial multilateral, na prática o protecionismo dos países dificulta o livre comércio. Assim, no âmbito deste estudo, a análise dos acordos preferenciais de comércio permite uma aproximação mais realista à forma como a intensificação comercial vem ocorrendo nas últimas décadas.

Como reação às dificuldades de conseguir avanços nas negociações multilaterais no âmbito da Organização Mundial do Comércio (OMC), houve, a partir dos anos 1990, a proliferação de acordos preferenciais de comércio. Esses arranjos podem ter alcance parcial ou geral e podem ser regionais, bilaterais ou plurilaterais. Burfisher et al. (2003, apud Lopes e Carvalho, 2010) afirmam que a análise de arranjos preferenciais é mais complexa, por consistir em um “exercício de 'segundo melhor” em relação à liberalização multilateral. Isso porque, enquanto algumas restrições ao comércio são eliminadas (como as tarifas dentro do arranjo), outras permanecem (subsídios e tarifas externas ao arranjo, por exemplo) (Lopes e Carvalho, 2010).

Após a proliferação de acordos regionais influenciados pela iniciativa europeia, a partir do final dos anos 1980, os acordos bilaterais (ou plurilaterais, quando realizados entre um país e um bloco) de alcance parcial tornaram-se uma tendência mundial. Esses arranjos surgiram como um elemento adicional para aumentar o acesso a mercados, sem exigir compromissos adicionais com blocos e acordos regionais. Além disso, possuem uma abrangência limitada, tanto no comprometimento quanto na possibilidade de liberalização de setores e produtos específicos com determinados países e blocos (Lopes e Carvalho, 2010).

Dessa forma, os acordos preferenciais de comércio com abrangência parcial podem possibilitar um maior bem-estar aos agentes neles engajados, pois tendem a incentivar os países a se especializarem na produção de bens em que possuem vantagem comparativa e permitem a eliminação do protecionismo em produtos dos quais dependem fortemente e nos quais o parceiro comercial tenha maior eficiência produtiva. Isso seria proporcionado pela eliminação de barreiras tarifárias preexistentes aos acordos e pela consequente redução de ineficiências alocativas. Como resultado, há aumento do volume do comércio externo, diversificação de produtos nos mercados nacionais e ganhos de bem-estar (Miyazaki, 2005; Lopes e Carvalho, 2010). No âmbito global, a proliferação dos acordos gera aumento da competitividade internacional e maior progresso na liberalização e na especialização comercial. 


\subsection{COMÉRCIO INTERNACIONAL E A DESINDUSTRIALIZAÇÃO}

O conceito de desindustrialização pode ser entendido como a redução persistente do emprego industrial no emprego total (Rowthorn e Ramaswamy, 1999, apud Oreiro e Feijó, 2010). Tregenna (2009) adiciona a esse conceito a condição de redução da participação do valor adicionado pela indústria no $\mathrm{PIB}^{1}$. Atualmente vem sendo debatido na literatura econômica se está ocorrendo um processo de desindustrialização no Brasil (Palma, 2005; Loures, Oreiro e Passos, 2006; Nassif, 2008; Bresser-Pereira e Marconi, 2008; Schwartsman, 2009; Oreiro e Feijó, 2010; Soares, Mutter e Oreiro, 2011). Entre as causas para o processo supracitado, consta o grau de integração comercial e produtiva dos países, embora haja poucos estudos relacionados a essa causa. Ou seja, o comércio internacional pode levar à especialização na produção de bens manufaturados, serviços e/ou produtos primários. Ainda, dependendo do padrão de comércio estabelecido, pode haver especialização na produção de produtos intensivos em trabalho qualificado ou não qualificado no setor da indústria de transformação (Oreiro e Feijó, 2010).

A literatura sobre o tema costuma mencionar causas internas e externas à desindustrialização (Oreiro e Feijó, 2010). A proposta deste trabalho, como mencionado anteriormente, é a de explorar as causas externas à desindustrialização, especificamente aquelas relacionadas ao aprofundamento do comércio internacional. Rowthorn e Ramaswamy (1999, apud Oreiro e Feijó, 2010) destacam duas vias pelas quais o comércio pode causar a desindustrialização. A primeira via seria através da especialização internacional da produção entre bens manufaturados e outros bens e serviços. Exemplificando, um país pode apresentar grandes déficits comerciais em bens produzidos pela indústria de transformação e apresentar superávits em outros bens, como nos produtos dos setores primários (agricultura, pecuária e extração) e/ou nos serviços. Tudo o mais constante, isso levaria a uma redução da participação da indústria de transformação na produção doméstica e no emprego total, ou seja, à desindustrialização. No caso do Brasil, a intensificação da exposição ao comércio internacional causaria a remoção da proteção de uma parte das empresas que atuam na indústria, a qual pode ser uma consequência remanescente do processo de substituição de importações, que ainda protege determinados setores da competição internacional. Quando essa proteção é removida pela simulação de livre comércio, passamos a importar bens de algumas indústrias mais eficientes ao redor do mundo. Isso acaba tirando do mercado as indústrias sem competitividade, o que dispensa trabalhadores e, consequentemente, causa a desindustrialização pelo conceito de redução do emprego na indústria de transformação.

\footnotetext{
Ao longo deste artigo, a desindustrialização será tratada com maior ênfase do ponto de vista do emprego.
} 
A segunda via pela qual o comércio internacional afetaria a estrutura do emprego seria a especialização dentro da própria indústria de transformação. De um lado, um determinado país pode se especializar na produção de bens que demande mão de obra mais qualificada e que, devido à produtividade desse tipo de trabalho obtida pelo alto padrão tecnológico, requeira um número menor de trabalhadores. Por outro lado, ao se especializar na produção de bens menos intensivos em trabalho qualificado, um número mais elevado de trabalhadores seria demandado. Portanto, se for estabelecido um padrão de comércio internacional no qual o país se especialize na produção de bens do primeiro “tipo", haverá redução da participação do emprego na indústria em relação ao emprego total, caracterizando também uma situação de desindustrialização. Isso é o que tem ocorrido em algumas economias avançadas devido aos avanços tecnológicos que são poupadores de mão de obra (Rowthorn e Ramaswamy, 1999, apud Oreiro e Feijó, 2010).

\section{METODOLOGIA}

\subsection{DADOS}

Para se atingir os objetivos traçados para este artigo, utilizaram-se duas bases de dados. A base do GTAP combina dados detalhados do comércio bilateral, de transporte e de proteção que caracterizam as relações econômicas entre as 129 regiões/países e os 57 setores do modelo ${ }^{2}$. Contém também as tabelas de insumo-produto para caracterizar as ligações entre os setores dentro de uma região. A versão 8, utilizada neste estudo, retrata a economia mundial no ano de $2007^{3}$. Utilizou-se também a classificação dos setores da CNAE 2.0 combinada com o nível de escolaridade do trabalho formal empregado no Brasil em cada setor, de acordo com os dados da RAIS do ano de 2007. Conforme Menezes-Filho e Muendler (2007), cerca de 97\% dos trabalhadores empregados formalmente no Brasil estão cobertos pela RAIS.

Embora a base de dados do GTAP permita a distinção entre trabalho qualificado e não qualificado na agregação dos fatores de produção, optou-se por juntá-los em um só fator. Isso porque essa distinção para os dados do Brasil é muito questionável, uma vez que, para a agricultura, foi utilizada a mesma distinção entre trabalho qualificado e não qualificado de Taiwan, e, para a indústria, foram utilizadas as mesmas propor-

\footnotetext{
2 Uma descrição detalhada da base de dados do GTAP pode ser encontrada em Narayanan et al. (2012).

3 Versão atual quando da elaboração deste trabalho.
} 
ções para indústria extrativa e de transformação (Liu et al., 1998). Para suprir tal deficiência, utilizaram-se os níveis de escolaridade do trabalho em cada setor, tendo como fonte a RAIS, como uma aproximação do tipo de qualificação que define o setor.

Dessa forma, a simulação com o GTAP proporciona a variação da alocação do fator trabalho nos diferentes setores produtivos (de acordo com a classificação do CNAE) após a realização dos choques. Com isso, multiplica-se a variação obtida pelo número de trabalhadores distribuídos em cada setor e divididos nos diferentes níveis de escolaridade extraídos dos dados da RAIS. Por fim, cria-se uma aproximação para a qualificação do trabalho de acordo com esses níveis de escolaridade. Segundo Winchester et al. (2003), a classificação do nível de qualificação do trabalho geralmente envolve algum grau de subjetividade do pesquisador. Aqui se adota a seguinte classificação: baixa (analfabeto a $5^{\circ}$ ano incompleto do ensino fundamental), médio-baixa ( $5^{\circ}$ ano completo do ensino fundamental a $9^{\circ}$ ano completo do ensino fundamental), médio-alta (ensino fundamental completo a ensino médio completo) e alta (ensino superior incompleto a superior completo, inclusive mestrado e doutorado), conforme demonstrado na Figura 1.

Figura 1 - Qualificação do Trabalho

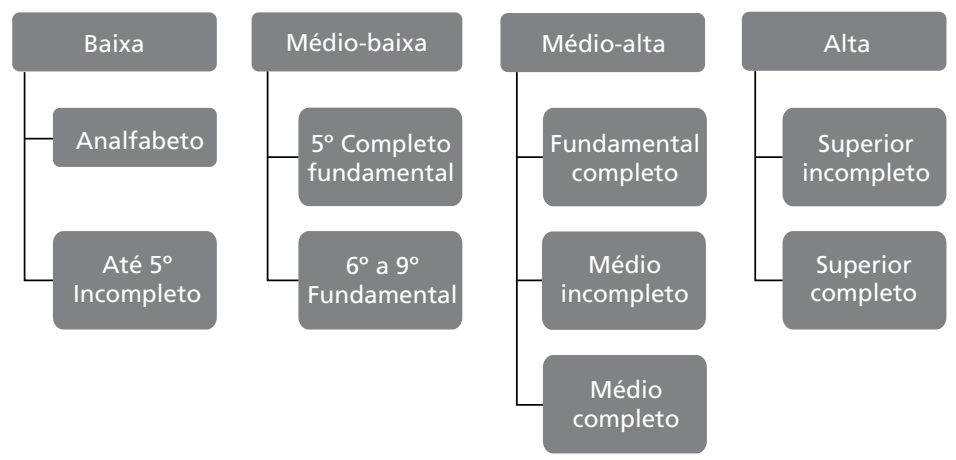

Fonte: Elaboração própria.

\subsection{O MODELO}

A teoria do equilíbrio geral pode ser compreendida como uma extensão do modelo de análise de oferta e de demanda de um mercado isolado para o caso de $n$ mercados. Trata-se, portanto, de uma tentativa de se relaxarem as hipóteses inerentes às análises de equilíbrio parcial, quando se assume que os preços dos demais mercados, que não aquele em análise, sejam constantes. Em equilíbrio geral, todos os preços são variáveis e a condição de equilíbrio requer que esses preços se ajustem às condições de oferta e demanda em seus respectivos mercados para que todos os mercados se equilibrem simultaneamente. Esse fato implica na necessidade de levarem consideração as carac- 
terísticas de cada mercado isoladamente e também as interações existentes entre todos os mercados.

Para executar as simulações, foi utilizado o GTAP ${ }^{4}$. Resumidamente, o GTAP é um modelo padrão multirregional de equilíbrio geral aplicável que assume retornos constantes de escala e competição perfeita nas atividades de produção e consumo. $\mathrm{O}$ funcionamento da economia global do GTAP pode ser explicado por meio da análise de uma região arbitrária e seus relacionamentos com as outras regiões, através da imposição de condições de equilíbrio entre os agentes globais. Em cada região existem $(j)$ indústrias utilizando $(i)$ fatores primários e $(i)$ insumos intermediários, tanto produzidos localmente quanto importados.

Os fatores primários são de propriedade dos agentes domésticos (representados por um "agente regional"), que também recebem todas as receitas de impostos recolhidas na região e fazem as devidas transferências para o resto do mundo. Os agentes alocam suas rendas para o consumo privado, para o consumo do governo (através do financiamento de todos os gastos do governo) e para a poupança. O governo utiliza os recursos disponibilizados pelo agente regional para comprar bens e serviços (domésticos e importados). Um sistema tributário impõe os impostos em cada transação e repassa a receita para o agente via transferências lump sum. Os exportadores compram mercadorias a preços de mercado, pagam impostos de exportação para o sistema tributário e vendem bens para um "comerciante global". Os comerciantes globais compram os bens das regiões exportadoras e os vendem para as regiões importadoras.

Nessa transação, os mesmos utilizam um serviço de transporte fornecido pelo "setor de transportes global”. Os importadores compram produtos produzidos ao redor do mundo dos comerciantes globais, pagam tarifas de importação para o governo local e vendem as mercadorias importadas aos vários agentes domésticos a preços de mercado. O modelo utiliza uma estrutura de "ninho" de três níveis na especificação da função de produção, conforme ilustrado na Figura 2.

No nível superior da árvore tecnológica invertida, tem-se a demanda pelo composto valor-adicionado e insumos intermediários. Como o modelo não admite substituição entre intermediários e valor-adicionado ${ }^{5}$, o efeito substituição causado pelo preço relativo é suprimido, ficando apenas o efeito expansão. Nesse nível da árvore tecnológica existem três tipos de mudança tecnológica. As variáveis ava $(j, r)$ e af $(i, j, r)$ referem-se, respectivamente, às mudanças tecnológicas nos insumos dos grupos valor-adicionado e intermediários; a variável $a o(j, r)$, à mudança tecnológica Hicks-neu-

4 Um detalhamento do modelo GTAP pode ser encontrado em Hertel (1997).

5 Essa simplificação resulta da suposição do modelo que assume uma função Leontief nesse nível de produção. 
tra. Essa última reduz o requerimento de insumo associado à produção de um dado nível de produto sem alterar a composição dos fatores de produção.

Figura 2 - Estrutura produtiva do GTAP6

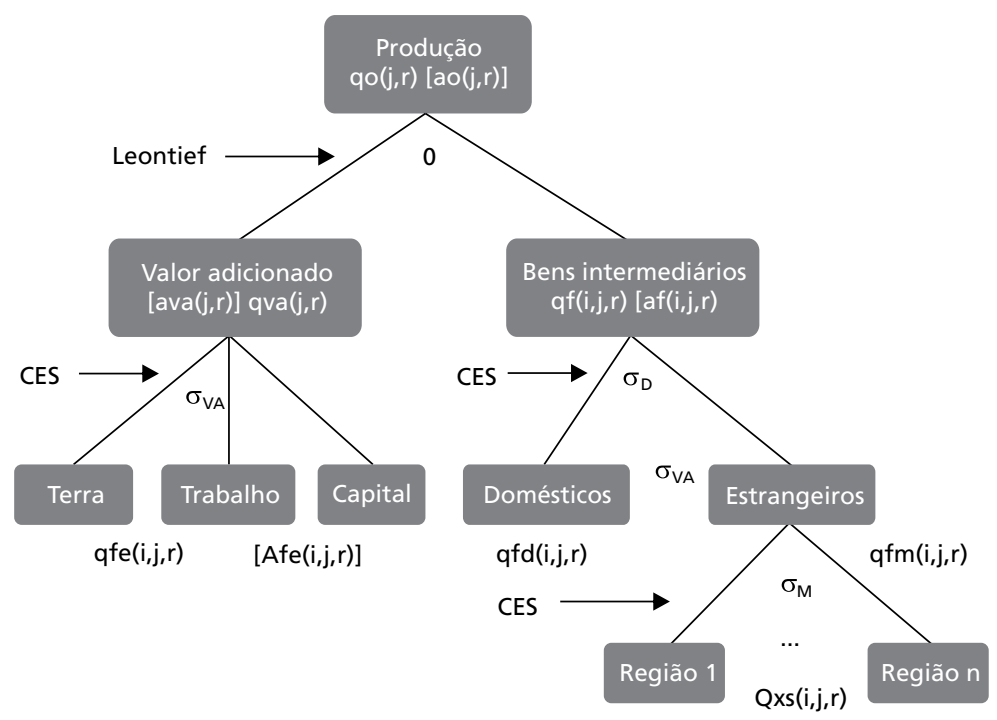

Fonte: Adaptado de Hertel (1997).

O segundo nível envolve uma elasticidade de substituição constante tanto entre os insumos intermediários como entre os fatores de produção $\left(\sigma_{V A}\right)$. Assume-se que os insumos importados são diferenciados por origem $\left(\sigma_{M}\right)$, assim como os insumos domésticos são discriminados em relação aos importados $\left(\sigma_{D}\right)$. Isto é, as firmas inicialmente determinam o mix ótimo de insumos domésticos e importados e somente depois decidem a respeito da origem das importações (hipótese de Armington) ${ }^{7}$. O nível mais baixo do ninho também assume uma elasticidade de substituição constante entre insumos importados de diferentes origens.

O modo como a remoção das barreiras tarifárias age sobre a demanda pelos produtos no modelo GTAP são muito bem explicadas por Coelho et al. (2006):

6 Existe uma estrutura de consumo similar a esta, com funções Cobb-Douglas, para a demanda do governo, e funções do tipo constant difference elasticity (CDE) para a demanda privada.

7 A estrutura de preferências de Armington implica que um bem produzido em uma região é um substituto imperfeito para bens produzidos pela mesma indústria em outras regiões. Ou seja, a mesma commodity, de diferentes fontes, pode ser comercializada a preços diferentes. 
Cada mercadoria $i$ importada tem um preço internacional $\left(p w m_{i}\right)$ sobre o qual incide, ao entrar em cada país/região, uma tarifa alfandegária (ad-valorem) a ela associada $\left(t_{i}\right)$, se houver, de modo que o preço internalizado desta mercadoria importada $\left(p m_{i}\right)$ é calculado conforme $p m=p w m+t{ }^{8}$ Portanto, uma variação da tarifa alfandegária provoca uma alteração inicial dos preços internalizados das mercadorias importadas, que afetam as decisões de demanda dos agentes econômicos internos de cada economia, os quais são sensíveis às mudanças nos preços relativos. Devido às inter-relações entre os agentes econômicos internos e externos, os efeitos das mudanças iniciais nas decisões de demanda se espalham por todo o sistema econômico. (Coelho et. al., 2006, p. 20)

\subsubsection{FECHAMENTO (CLOSURE) E AGREGAÇÃO}

O fechamento, ou closure, de um cenário, pode ser considerado como uma maneira especial de escolha das variáveis endógenas e exógenas do modelo. Para que a resolução do modelo alcance uma solução, é necessário que o número de equações seja igual ao número de variáveis endógenas. Como o número de variáveis geralmente é superior ao número de equações, devem ser selecionadas algumas variáveis para serem exógenas ao modelo (fixas). Os fatores de produção que têm mobilidade entre os setores são capital e trabalho. O grau de mobilidade desses fatores de produção é governado por uma elasticidade de transformação constante. Terra é o fator de produção imóvel.

Os critérios de agregação utilizados para simulações de EGC dependem basicamente do interesse do pesquisador. As agregações utilizadas neste trabalho podem ser observadas na Tabela 1.

O equilíbrio inicial foi caracterizado pela economia no ano de 2007, de acordo com a base de dados do GTAP na versão 8. Na agregação em nível regional, procurou-se observar o comércio do Brasil com os principais parceiros comerciais, que foram deixados como regiões/países isolados, e com outros blocos e regiões, que podem evidenciar algum padrão de especialização. A agregação setorial foi realizada de forma a identificar a questão da desindustrialização. Para isso, foram agrupados os três grandes setores (primário, indústria de transformação e serviços), para permitir uma posterior desagregação do setor primário e da indústria de transformação.

\footnotetext{
8 Nota dos autores: no caso de um subsídio, $t$ assumiria um valor negativo.
} 


\subsubsection{CENÁRIOS}

Foram estabelecidos dois cenários neste estudo. O primeiro cenário simula a remoção total de tarifas e subsídios entre todas as 12 regiões do modelo. $\mathrm{O}$ objetivo da construção deste cenário consiste em verificar a tendência de longo prazo do padrão de especialização mundial, em especial a do Brasil, em um mundo de livre comércio. $\mathrm{O}$ segundo simula acordos preferenciais de comércio do Brasil, também através da remoção das tarifas e dos subsídios, com as outras 11 regiões desagregadas na Tabela 1 . O objetivo deste segundo cenário é o de explorar a questão das vantagens comparativas e da complementaridade de mercados produtores do Brasil com os mercados das demais regiões e como isso afetaria a alocação do trabalho formal.

Tabela 1 - Agregação regional e setorial

\section{AGREGAÇÃO REGIONAL}

1. Brasil

2. China

3. Índia

4. RAsia (Resto da Ásia)

Coreia do Sul, Tailândia, Japão, Taiwan, Indonésia, Malásia, Singapura, Vietnã, Hong Kong, Camboja, Laos, Burma, Filipinas, Bangladesh, Paquistão, Sri Lanka, Resto do Leste da Ásia, Resto do Sul da Ásia, Resto do Sudeste da Ásia.

\section{Oceania}

Austrália, Nova Zelândia, Resto da Oceania.

6. EUA (Estados Unidos da América)

7. RAmerNorte (Resto da América do Norte)

México, Canadá, Resto da América do Norte.

8. RAmerLatina (Resto da América Latina)

Argentina, Uruguai, Peru, Venezuela, Paraguai, Bolívia,

Equador, Costa Rica, Guatemala, Nicarágua, Panamá, Chile, Colômbia, Resto da América do Sul, Resto da América Central, Resto do Caribe.

\section{EU_25 (União Europeia)}

Áustria, Bélgica, Dinamarca, Finlândia, França, Alemanha, Reino Unido, Grécia, Irlanda, Itália, Luxemburgo, Holanda, Portugal, Espanha, Suécia, Chipre, Hungria, Malta, Polônia, Eslováquia, Eslovênia, Estônia, Letônia, Lituânia, República Tcheca.

10. OMeNA (Oriente Médio e Norte da África)

Irã, Turquia, Egito, Marrocos, Tunísia, Resto da Ásia Ocidental, Resto do Norte da África.

11. ASS (África Subsaariana)

Nigéria, Senegal, Resto da África Ocidental, África Central, Sudoeste da África, Etiópia, Madagascar, Malaui, Ilha Maurício, Moçambique, Tanzânia, Uganda, Zâmbia, Zimbábue, Resto da África Oriental, Botsuana, África do Sul, Resto da União África do Sul.

12. Resto do Mundo (RdM)

Suíça, Noruega, Resto do EFTA, Albânia, Bulgária, Croácia, Romênia, Belarus, Federação Russa, Ucrânia, Resto da Europa Oriental, Resto da Europa, Cazaquistão, Resto da Antiga União Soviética, Quirguistão, Armênia, Azerbaijão, Geórgia.

\section{AGREGAÇÃO SETORIAL}

\section{Setor primário}

1.1. Agropecuário: cana-de-açúcar, milho, arroz com casca, arroz processado, trigo, outros cereais em grão, vegetais, frutas e nozes, fibras à base de plantas, outras colheitas, bovinos, ovinos, caprinos, equinos, outros produtos animais, leite não processado, lã, bicho-da-seda, produtos da carne bovina, outros produtos da carne, óleos e gorduras vegetais, produtos diários, outros produtos alimentícios, bebidas e tabaco.

1.2. Indústria Extrativa: silvicultura, pesca, carvão, petróleo, gás natural, minerais.

\section{Indústria de transformação}

2.1. Indústria Alimentícia: açúcar, óleos vegetais e gorduras, produtos diários, bebidas e produtos do tabaco, outros produtos alimentícios.

2.2. Indústria Têxtil: têxteis e vestuário.

2.3. Indústria Leve: produtos de couro, produtos de madeira, produtos de papel, publicações, produtos de metal, veículos e suas partes, outros equipamentos de transporte, outras manufaturas.

2.4. Indústria Pesada: produtos derivados do petróleo e carvão, produtos químicos, de borracha e de plástico, outros produtos minerais, metais ferrosos, outros metais, equipamentos eletrônicos, outras máquinas e equipamentos.

\section{Serviços}

Eletricidade, produção e distribuição de gás natural, água, construção, comércio, transporte aquático, transporte aéreo, outros transportes, comunicação, outros serviços financeiros, seguros, outros negócios, recreação e outros serviços, administração pública e defesa, educação, saúde, habitação. 


\section{RESULTADOS}

\subsection{IMPACTOS DO LIVRE COMÉRCIO MUNDIAL}

Como estabelecido no objetivo deste trabalho, os primeiros resultados a serem explorados tentam buscar alguma evidência do padrão de alocação do emprego e de comércio que se estabeleceria em decorrência de um comércio mundial livre, como uma aproximação à tendência de intensificação comercial. Nesse sentido, a Tabela 2 mostra as variações percentuais na demanda por trabalho decorrentes da eliminação total das tarifas de importação e dos subsídios à exportação entre todas as regiões do modelo, nos setores estabelecidos na agregação.

Tabela 2 - Variação percentual na demanda por trabalho nos três grandes setores

\begin{tabular}{lccc}
\hline \multicolumn{1}{c}{ Regióes } & Primário & Ind. Transf. & Serviços \\
\hline Brasil & 4,02 & $-1,33$ & 0,07 \\
China & $-2,21$ & 0,22 & 0,67 \\
Índia & $-8,69$ & 5,6 & 0,56 \\
RAsia & $-9,2$ & 0,72 & 0,26 \\
Oceania & $-3,2$ & 1,94 & $-0,09$ \\
EUA & 5,34 & $-0,71$ & 0,05 \\
RAmericaN & 1,43 & 0,2 & $-0,12$ \\
RAmerLatin & $-1,28$ & $-0,07$ & 0,22 \\
UE_25 & $-5,13$ & $-0,33$ & 0,31 \\
OMeNA & $-3,79$ & 2,46 & 0,34 \\
ASS & $-1,06$ & $-0,9$ & 0,77 \\
RdM & 9,13 & $-4,02$ & $-0,2$ \\
\hline
\end{tabular}

Fonte: Elaboração própria com resultados da simulação.

Essa simulação evidencia que Brasil, EUA, Resto da América Latina, União Europeia, África Subsaariana e Resto do Mundo teriam a demanda pelo fator trabalho reduzida no setor da indústria de transformação. À parte o Resto do Mundo, o Brasil seria a região onde essa redução ocorreria de forma mais pronunciada (1,33\%). Por outro lado, países/regiões como China, Índia, Oceania e Oriente Médio e Norte da África teriam a demanda por trabalho aumentada em função dessa simulação. Esses resultados preliminares podem sugerir certo padrão de especialização mundial que ocasionaria uma realocação da mão de obra do setor da indústria de transformação para os setores primários e de serviços no Brasil; ou seja, uma contribuição do livre comércio à desindustrialização no Brasil.

Uma questão que vem sendo debatida no meio acadêmico é a de que a desindustrialização, apesar de ser um fenômeno normal em economias desenvolvidas, no Brasil estaria acontecendo precocemente, deslocando a mão de obra do setor da indústria para 
os setores com baixa exigência de qualificação (Oreiro e Feijó, 2010). De forma geral, no Gráfico 1, observa-se que os trabalhadores com níveis de escolaridade mais baixos predominam no setor primário, enquanto os de níveis mais altos, no setor de serviços.

Gráfico 1 - Nível de escolaridade nos três grandes setores

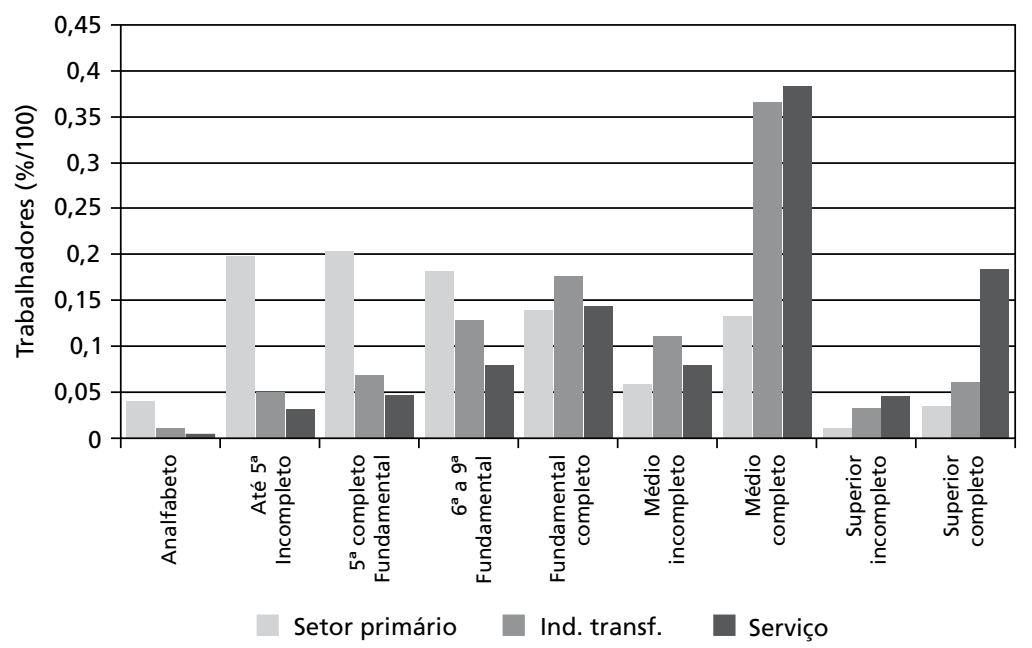

Fonte: Elaboração própria com base nos dados da RAIS.

A indústria de transformação, de certa forma, apresenta-se como um setor demandante de mão de obra com qualificação média (especialmente médio-alta), apresentando, por exemplo, demandas de 13\%, 18\%, 11\% e 36\% para, respectivamente, escolaridade de $6^{\mathrm{a}}$ a $9^{\mathrm{a}}$ fundamental, fundamental completo, médio incompleto e médio completo. Para relativizar esses números e se ter uma ideia do que representam esses percentuais em termos de demanda total por trabalho no Brasil, o setor de serviços apresenta uma demanda de 78,1\%, o setor da indústria de transformação $17,6 \%$, e o setor primário apenas 4,3\%, de um total de 37.607.430 trabalhadores cadastrados na RAIS ${ }^{9}$ em 2007, ano-base dos choques realizados no presente estudo.

Uma vez que foram verificados indícios de desindustrialização no Brasil nos primeiros resultados, a próxima etapa do trabalho consistiu em aprofundar a análise para o Brasil. Nesse sentido, foram feitas duas modificações na agregação da base de dados do GTAP, conforme se verifica na Tabela 1. A primeira desagregou o setor primário

9 O setor primário possui apenas 4,3\% dos trabalhadores porque nesse setor predomina a mão de obra informal. Conforme CIA World Factbook (est. 2011), a distribuição do trabalho no Brasil ocorre da seguinte forma: $15,7 \%$ na agricultura, $13,3 \%$ na indústria e $71 \%$ nos serviços. 
em dois setores: o setor agropecuário e o setor da indústria extrativa. A segunda desagregou o setor da indústria de transformação em quatro outros setores, os quais são: indústria alimentícia, indústria têxtil, indústria leve e indústria pesada ${ }^{10}$. Da mesma forma, foi feita a compatibilização dessa desagregação nos setores da CNAE, de maneira a interligar os resultados das simulações com os níveis de escolaridade em cada setor. Posteriormente, os níveis de escolaridade serão apresentados de forma agregada em quatro níveis de qualificação do trabalho, conforme já ilustrado na Figura 1.

Observa-se, na Tabela 3, uma realocação da demanda pelo fator trabalho dos setores industriais para os setores de serviços e agropecuário. O último aumentaria sua demanda por trabalho em $11,14 \%$, possivelmente absorvendo parte da mão de obra dispensada pelos setores da indústria extrativa (5\%) e da indústria de transformação (1,33\% - Tabela 2). A variação do valor adicionado nessas indústrias teve comportamento semelhante. É interessante notar que também ocorreria uma realocação dentro do próprio setor da indústria de transformação, ou seja, a indústria alimentícia absorveria parte do trabalho e do valor adicionado (aumentos de 5,3\% e 5,1\%, respectivamente) abandonados pelos outros setores da indústria de transformação.

Tabela 3 - Variação percentual em variáveis selecionadas, Brasil

\begin{tabular}{lcccc}
\hline Setores & Dem. Trab. & V. Adicion. & Export. & Import. \\
\hline Agropecuário & 11,14 & 9,33 & 40,17 & 29,02 \\
Ind.Extrativa & -5 & $-3,65$ & $-2,6$ & $-1,33$ \\
Ind.Alimentos & 5,29 & 5,08 & 35,48 & 28,26 \\
Ind.Têxtil & $-7,73$ & $-7,85$ & $-9,74$ & 60,19 \\
Ind.Leve & $-0,85$ & $-1,08$ & 16,73 & 37,96 \\
Ind.Pesada & $-4,31$ & $-4,56$ & 9,52 & 27,64 \\
Serviços & 0,08 & $-0,15$ & $-8,84$ & 5,03 \\
\hline
\end{tabular}

Fonte: Elaboração própria com base nos resultados da simulação.

Esses resultados são provenientes da eliminação das distorções causadas pelos tributos de importação e pelos subsídios. Como se trata da utilização de um modelo walrasiano, os efeitos reais completos da remoção dessas distorções se concretizariam em um horizonte de longo prazo, após o ajuste de todos os preços da economia. Esses efeitos podem ser evidenciados, por exemplo, pelas variações observadas nos valores das exportações e das importações. Em geral, podem-se observar aumentos significativos nas exportações dos setores que tiveram eliminadas tarifas de importação que impediam a entrada de produtos brasileiros em seus territórios. Isso pode ser obser-

\footnotetext{
${ }^{10}$ Esta classificação foi proposta na base de dados do GTAP, versão 8.0.
} 
vado na base de dados do GTAP, na qual, antes da simulação, verificam-se tarifas médias praticadas para o setor agropecuário de, por exemplo, 10,1\%, 9,2\%, 9,1\%, 5,8\% e 6,8\%, pela China, Índia, Resto da Ásia, EUA e União Europeia, respectivamente. Por outro lado, os setores nos quais se observam aumentos nas importações são aqueles mais protegidos internamente por tarifas altas. Nesse sentido, por exemplo, para o setor da indústria têxtil têm-se tarifas médias praticadas pelo Brasil de 10,6\%, 16,8\% e 30,8\% para China, Índia e Resto da Ásia, respectivamente.

Um simples cálculo de multiplicação dos resultados da simulação apresentados na Tabela 3 pelos dados da RAIS ilustra o impacto que a liberalização total do comércio internacional teria sobre o emprego nos setores selecionados para a simulação, assim como o impacto no nível de escolaridade dos trabalhadores demandados pelos mesmos setores. Os níveis de escolaridade foram agregados em quatro níveis de qualificação do trabalho, conforme já ilustrado na Figura 1, de forma a possibilitar a análise da realocação do trabalho nos diferentes setores e em seus diferentes níveis de qualificação (Gráfico 2).

Foi assumido que o impacto das variações da demanda por trabalho nos setores, obtidas pela simulação desse cenário, distribui-se entre os graus de qualificação do trabalho, de acordo com a participação desses últimos em cada setor. Observa-se que os setores das indústrias extrativa, têxtil, leve e pesada teriam a demanda por trabalho diminuída, enquanto a mesma aumentaria nos setores agropecuário, da indústria alimentícia e no de serviços. Isso significa, de forma geral, um padrão de especialização do trabalho no Brasil estabelecido nas atividades relacionadas a esses últimos setores.

Em se tratando da qualificação do trabalho demandado que sofreria variações em decorrência dessa simulação, podem ser observados alguns resultados interessantes. Ocorreriam aumentos na demanda por trabalho com qualificações baixa, médio-baixa e médio-alta, principalmente pelo setor agropecuário e pela indústria alimentícia. As maiores variações representariam aumentos de 42.608, de 58.886 e de 37.875 trabalhadores com qualificações, respectivamente, médio-alta, médio-baixa e baixa no setor agropecuário e de 40.317 trabalhadores de qualificação médio-alta na indústria alimentícia $^{11}$. Entretanto, haveria uma redução de demanda de 74.023 e de 51.312 trabalhadores com nível de qualificação médio-alta nas indústrias pesada e têxtil, respectivamente. O setor de serviços apresentaria ganhos de participação no emprego em todos os níveis de qualificação, com destaque para a qualificação médio-alta (14.259 trabalhadores). Quando a análise se mantém somente no setor da indústria de transformação como um todo, observa-se uma redução líquida de 121.752 postos de trabalho, sendo que mais de

\footnotetext{
${ }^{11}$ Essa informação será defrontada, posteriormente, com os efeitos das simulações de livre comércio do Brasil com as outras regiões do modelo isoladamente.
} 
40\% no nível de escolaridade médio completo (53.184), e mais de 70\% no nível de qualificação médio-alta (94.850).

\section{Gráfico 2 - Impacto do livre comércio sobre a demanda por nível de qualificação do trabalho}

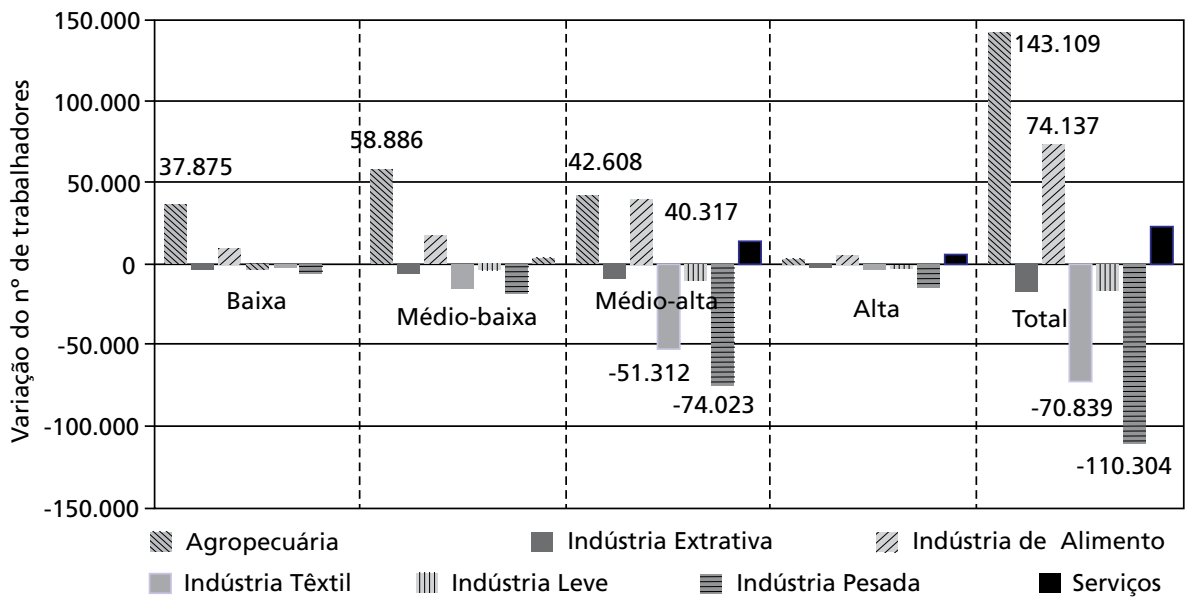

Fonte: Elaboração própria com base nos resultados da simulação e em dados da RAIS

Portanto, observa-se que a principal realocação seria do emprego de nível de qualificação médio-alta, do setor da indústria de transformação para os setores agropecuário, da indústria de alimentos e de serviços. O trabalho de baixa e médio-baixa qualificação liberado pelos setores que sofreram os impactos negativos da liberação comercial seria absorvido pelos setores agropecuário e indústria alimentícia, especialmente pelo primeiro. $\mathrm{O}$ trabalho de alta qualificação seria absorvido, principalmente, pela indústria alimentícia e pelo setor de serviços. Essa exposição ilustra, em boa medida, a adequação dos resultados ao referencial teórico acerca dos efeitos do comércio internacional sobre a demanda por trabalho e à desindustrialização.

\subsubsection{ANÁLISE DE BEM-ESTAR}

A fonte de variação de bem-estar gerada no GTAP é resultado, por exemplo, da retirada ou da imposição de distorções (impostos, subsídios e taxas), ou então devido a variações na condição tecnológica de determinado mercado em dada região. O tamanho do ganho/perda de bem-estar associado à retirada de uma distorção é uma função do tamanho da distorção inicial, da magnitude dessa variação, e da sensibilidade de resposta do mercado atingido por tal mudança. A Variação Equivalente $(E V)$ asso- 
ciada com uma perturbação no modelo GTAP (medida utilizada como proxy para o bem-estar econômico) é igual à diferença entre a despesa requerida para obter o novo nível de utilidade (após a simulação) aos preços iniciais $\left(Y_{E V}\right)$ e o nível de utilidade disponível no equilíbrio inicial ( $Y$ ), ou seja, $E V=Y_{E V}-Y(\mathrm{McDougall}, 2002)$. Essa medida pode ser decomposta em três componentes: efeitos alocativos, termos de troca e o saldo investimento-poupança.

O efeito total de bem-estar produziu um montante de US\$ 3,54 bilhões. A decomposição desse montante fica distribuída em efeitos alocativos (US\$ 2,14 bilhões), termos de troca (US\$ 2,05 bilhões) e saldo investimento-poupança (- US\$ 0,65 bilhão). Os efeitos alocativos, que mostram a parcela do bem-estar que é proveniente dos ganhos de eficiência, são ocasionados pela remoção das distorções causadas pela incidência de tarifas sobre o comércio. Produtos domésticos e importados mais baratos, por exemplo, provocam ganhos tanto através do consumo ampliado das famílias e do governo, quanto na forma como os recursos produtivos domésticos são aplicados pelas empresas. O Gráfico 3 ilustra que os ganhos alocativos adviriam da indústria de transformação, especialmente das indústrias pesada e leve. Cabe lembrar que é justamente nessa indústria onde ocorrem as reduções mais importantes na demanda por trabalho. No contexto deste trabalho, isso significa que parte desse fator está sendo alocado de forma ineficiente dentro da indústria de transformação, e isso só é possível através da proteção da mesma com tarifas relativamente altas em termos globais.

\section{Gráfico 3 - Efeitos alocativos e de termos de troca nos setores produtivos}

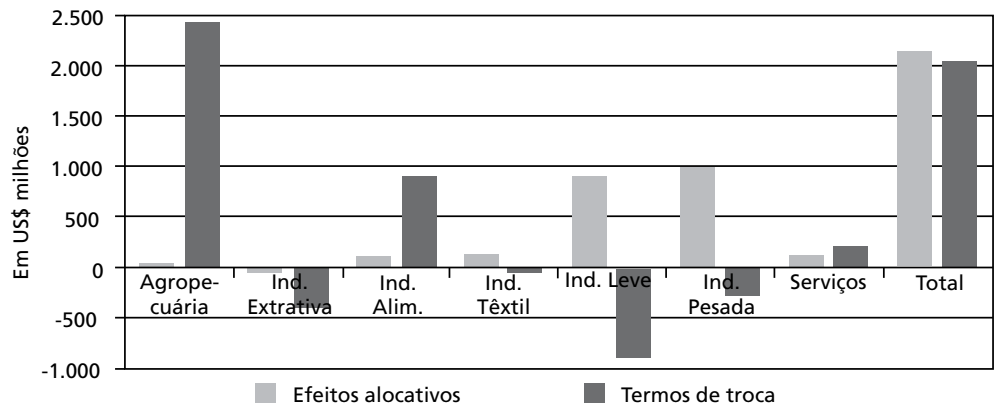

Fonte: Elaboração própria com base nos resultados da simulação.

Neste modelo, a variação nos termos de troca é dada pela diferença entre as variações percentuais dos índices de preço recebido e pago pelos tradables produzidos e usados, respectivamente, em determinada região. $\mathrm{O}$ setor agropecuário seria o mais beneficiado nesse quesito, seguido pela indústria alimentícia e pelo setor de serviços. Ou seja, em média, os preços dos bens produzidos nesses setores aumentariam relati- 
vamente aos bens importados, devido ao aumento da demanda mundial pelos nossos produtos, ceteris paribus.

\subsection{IMPACTOS DE ARRANJOS COMERCIAIS PREFERENCIAIS}

Um acordo preferencial de comércio tende a incentivar um país a se especializar na produção de bens em que possua vantagem comparativa e a incentivar a complementaridade dos mercados. No contexto deste trabalho, que utiliza um modelo com rendimentos constantes de escala, a estrutura produtiva do país se alteraria em decorrência do aumento da competição entre as firmas. Isso seria proporcionado pela eliminação de barreiras tarifárias preexistentes antes dos acordos e pela conseqüente redução de ineficiências alocativas ${ }^{12}$. Para obter esses impactos, foram rodados 11 experimentos simulando a eliminação de tarifas e subsídios do Brasil com as outras 11 regiões do modelo isoladamente. Essas simulações têm o intuito de mostrar o perfil de especialização e o impacto no emprego que adviria em decorrência de acordos com diferentes parceiros comerciais (Tabela 4).

Tabela 4 - Variação percentual da demanda por trabalho do Brasil decorrente de acordos bilaterais de comércio

\begin{tabular}{lccccccc}
\hline Regiões & Agropecuário & $\begin{array}{c}\text { Ind. } \\
\text { Extrativa }\end{array}$ & $\begin{array}{c}\text { Ind. } \\
\text { Alim }\end{array}$ & $\begin{array}{c}\text { Ind. } \\
\text { Têxtil }\end{array}$ & $\begin{array}{c}\text { Ind. } \\
\text { Leve }\end{array}$ & $\begin{array}{c}\text { Ind. } \\
\text { Pesada }\end{array}$ & Serviços \\
\hline China & 0,42 & 0,82 & 0,23 & $-3,34$ & 0,07 & $-0,69$ & 0,09 \\
Índia & 0,17 & $-0,11$ & 0,59 & $-0,69$ & $-0,12$ & $-0,38$ & 0,04 \\
RAsia & 11,14 & $-2,64$ & $-0,94$ & $-2,57$ & $-3,21$ & $-2,93$ & 0,17 \\
Oceania & $-0,02$ & $-0,02$ & $-0,01$ & 0 & 0,01 & 0,02 & 0 \\
EUA & 0,15 & $-0,7$ & $-0,16$ & 0,55 & 0,52 & $-0,32$ & $-0,01$ \\
RAmerNorte & $-0,36$ & $-0,38$ & $-0,16$ & 0,45 & 0,46 & 0,07 & $-0,03$ \\
RAmerLatin & $-0,97$ & $-1,79$ & 1,78 & 0,07 & 1,68 & $-0,17$ & $-0,09$ \\
EU_25 & 5,08 & $-1,53$ & 0,83 & $-1,57$ & $-0,9$ & $-2,17$ & 0,09 \\
OMeNA & 1,54 & $-0,71$ & 0,92 & $-0,45$ & $-0,27$ & $-0,59$ & 0 \\
ASS & $-0,18$ & $-0,85$ & 1,06 & $-0,36$ & 0,28 & $-0,07$ & $-0,02$ \\
RdM & 3,31 & $-1,64$ & 4,18 & $-0,94$ & $-1,3$ & $-1,63$ & 0,04 \\
\hline
\end{tabular}

Fonte: Elaboração própria com base nos resultados da simulação.

12 Diferentemente de um modelo de competição imperfeita, no qual os ganhos do comércio viriam também das economias de escala proporcionadas pelo aumento do tamanho dos mercados consumidores. Os resultados viriam a ser majorados em função disso, entretanto, seriam necessárias estimativas precisas de mark-up para os setores utilizados, além de envolver um trabalho computacional dispendioso em termos de tempo. 
Assim, verifica-se que o maior impacto negativo na demanda por trabalho na indústria de transformação decorre dos acordos com o Resto da Ásia, com a União Europeia e com a China. Da primeira região citada, advém o maior impacto positivo na demanda por trabalho pelo setor agropecuário.

\section{Gráfico 4 - Arranjos comerciais e a variação do trabalho por nível de qualificação no Brasil}

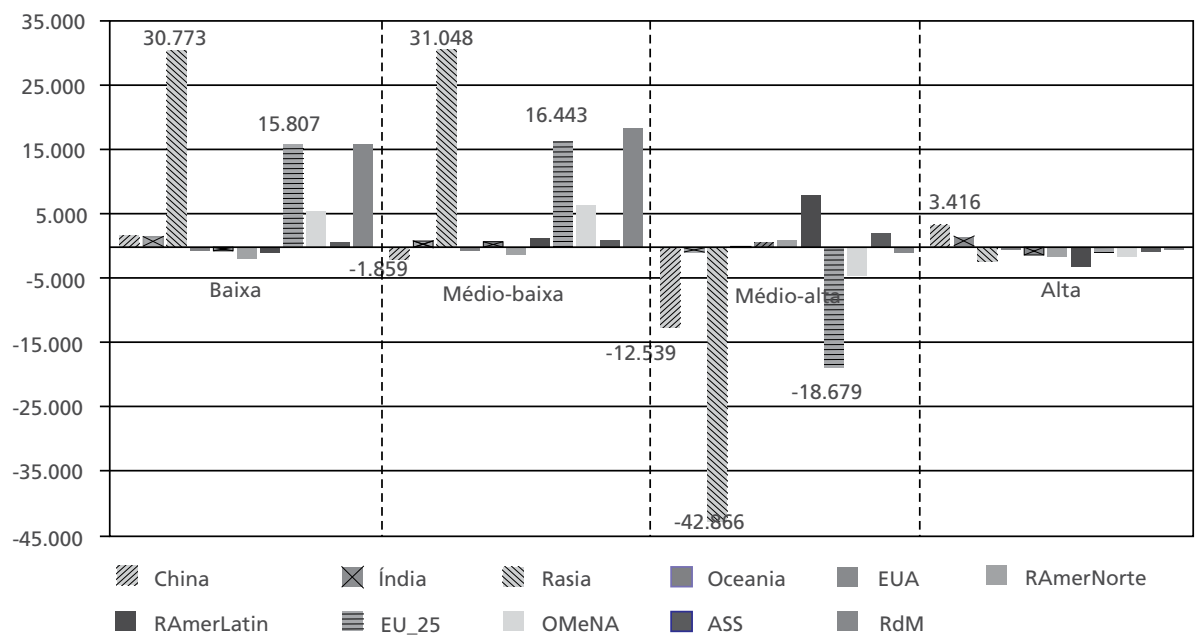

Fonte: Elaboração própria com base nos resultados da simulação e em dados da RAIS.

Trazendo a análise para a questão da qualificação do trabalho (Gráfico 4), por um lado, o acordo de livre comércio com a UE impactaria significativamente de forma positiva a demanda por trabalho de médio-baixa (16.443) e de baixa (15.807) qualificações, basicamente devido ao estímulo do setor agropecuário (5,1\% - Tabela 4) no Brasil proporcionado pela eliminação das barreiras tarifárias. Por outro lado, esse acordo impactaria negativamente o emprego de qualificações médio-alta (18.679) e alta (910), em função da expressiva queda de atividade das indústrias pesada, leve e têxtil.

$\mathrm{O}$ acordo com a China impactaria negativamente a demanda por trabalho de qualificações médio-alta (12.539) e médio-baixa (1.859). Esses resultados viriam basicamente da queda de atividade das indústrias têxtil (3,3\% - Tabela 4) e pesada, devido à importância da China na balança comercial brasileira nesses setores. No entanto, haveria impactos positivos na demanda por trabalho de qualificações alta (3.416) e baixa (1.736), pelo impacto positivo no setor primário, na indústria alimentícia e no setor de serviços (este com característica de alta e médio-alta qualificações).

Como mencionado anteriormente (ver Tabela 4), é no acordo com o Resto da Ásia (RAsia) que ocorreriam as variações da demanda por trabalho mais significantes, 
tanto positivas quanto negativas. As positivas, proporcionadas pelo setor agropecuário, aumentariam a demanda por trabalho nos níveis de baixa (30.773) e de médiobaixa (31.048) qualificações. As negativas, devido à queda de atividade na indústria de transformação, diminuiriam principalmente a demanda por trabalhadores com médio-alta qualificação (42.866).

\section{Gráfico 5 - Acordos preferenciais de comércio e a variação do trabalho por nível de qualificação na indústria de transformação do Brasil}

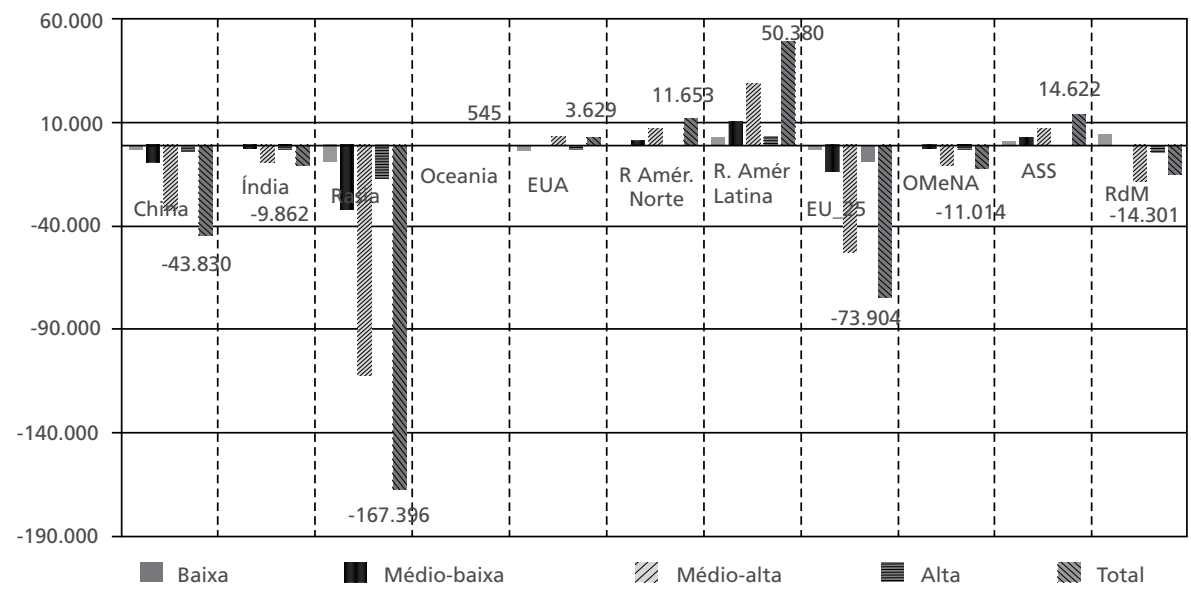

Fonte: Elaboração própria com base nos resultados da simulação e em dados da RAIS

Através da observação do Gráfico 5, o qual consiste em uma análise apenas da indústria de transformação, pode-se verificar quais arranjos comerciais auxiliariam o processo de desindustrialização. Haveria redução significativa no emprego da indústria de transformação (especificamente na têxtil, leve e pesada) proveniente de acordos com o Resto da Ásia, União Europeia, China, Índia, Oriente Médio e Norte da África, e Resto do Mundo. Um acordo de livre comércio com o Resto da Ásia teria o maior impacto negativo sobre o emprego na indústria de transformação (167.396 trabalhadores), em todos os níveis de qualificação, sendo a maioria no nível médio-alto. Esse resultado é proveniente da maior concentração de trabalhadores com qualificação média no setor da indústria de transformação, conforme mostrado anteriormente nos Gráficos 1 e 2. Os resultados positivos em termos de emprego viriam dos acordos com a Oceania, EUA, Resto da América do Norte, Resto da América Latina (o mais expressivo, em 50.380) e África Subsaariana, o que evidencia certa vantagem comparativa do Brasil na produção industrial em relação a essas regiões. O acordo com o Resto da América Latina teria o maior impacto positivo na demanda por trabalho de qualificação médio-alta. 


\section{ANÁLISE DE SENSIBILIDADE}

Em simulações econômicas implementadas em modelos EGC, os resultados são fortemente influenciados pelas suposições que se fazem para alguns parâmetros e pelos choques em variáveis exógenas. Assim, fazer variar esses elementos para se verificar o quanto eles influenciam os resultados endógenos é uma tarefa indispensável para dar credibilidade às conclusões acerca dos resultados encontrados. Portanto, a análise de sensibilidade trata-se de um importante instrumento para verificar a robustez dos resultados encontrados pelos modelos EGC.

Uma forma de executar a análise de sensibilidade, proposta inicialmente por Wigle (1991), é a análise de sensibilidade sistemática. Nessa, o modelo é resolvido várias vezes para os diferentes valores dos parâmetros ou choques, dentro de um intervalo preestabelecido, e a distribuição dos valores obtidos para cada variável endógena é sumarizada através da sua média e desvio padrão.

Para fazer a análise de sensibilidade neste trabalho, foram escolhidos os parâmetros elasticidade de substituição entre os insumos domésticos e importados (ESUBT) e elasticidade de substituição entre os insumos domésticos (ESUBD) do cenário que simula a eliminação completa de tarifas e subsídios entre todas as regiões do modelo, ou seja, o cenário de livre comércio. Foi estabelecida uma variação de $30 \%$ para cima e para baixo nesses parâmetros. Os resultados sobre a variação do emprego do fator trabalho nos setores do modelo são mostrados na Tabela 5.

Tabela 5 - Análise de sensibilidade nos parâmetros ESUBT e ESUBD

\begin{tabular}{lccc}
\hline Setores & Limite inferior & Limite superior & Amplitude \\
\hline Agropecuário & 10,51 & 11,77 & 1,26 \\
Ind. Extrativa & $-5,32$ & $-4,68$ & 0,64 \\
Ind. Alimentos & 4,91 & 5,67 & 0,76 \\
Ind. Têxtil & $-8,52$ & $-6,94$ & 1,58 \\
Ind. Leve & $-1,35$ & $-0,35$ & 1,00 \\
Ind. Pesada & $-4,74$ & $-3,88$ & 0,86 \\
Serviços & 0,06 & 0,10 & 0,04 \\
\hline
\end{tabular}

Fonte: Elaboração própria com base nos resultados da simulação.

Observa-se, em primeiro lugar, que não houve troca de sinal entre os limites inferior e superior, o que consiste em uma evidência de robustez do modelo proposto. Além disso, não houve mudanças significativas nos valores apresentados na Tabela 2. As maiores amplitudes de variação de resultados no emprego aconteceram nos setores agropecuários, na indústria têxtil e na indústria leve, em função das maiores magnitudes dos valores iniciais médios. Ou seja, os resultados mostrados ao longo do trabalho 
não mudariam muito se o modelo fosse calibrado com parâmetros um pouco diferentes daqueles constantes na base de dados. As magnitudes dos resultados reportados neste estudo são influenciadas predominantemente pelo "tamanho" das tarifas e dos subsídios que foram eliminados em função dos choques implementados.

\section{CONCLUSÃO}

O objetivo deste estudo foi explorar uma das causas externas à desindustrialização aquela relacionada à intensificação do comércio internacional - a partir da simulação de dois cenários: um de livre comércio mundial, e outro de acordos preferenciais de comércio. A importância de se conhecer o padrão de especialização do trabalho que poderia surgir em função de um aprofundamento do processo de abertura comercial deve-se à possibilidade de identificar os setores produtivos mais vulneráveis em termos de demanda por diferentes níveis de qualificação de trabalho formal. Isso é proporcionado pela simulação com modelos de EGC, após o ajuste de todos os mercados e em todas as regiões, através de uma análise de estática comparativa dos resultados antes e depois dos choques implementados.

O choque de livre comércio mostra que, nesse cenário, haveria uma redução da demanda por trabalho na indústria de transformação, predominantemente no nível de qualificação médio (em especial, médio-alto), devido ao impacto negativo na produção e no valor adicionado nas indústrias têxtil, leve e pesada, que são os setores mais protegidos por tarifas de importação. Tal evidência ocorreu também devido ao padrão de qualificação médio que predomina no Brasil no setor da indústria de transformação. Os trabalhadores com esse perfil seriam realocados para o setor agropecuário e da indústria alimentícia, que apresentam um perfil de médio-baixa qualificação, e para o setor de serviços, com característica de médio-alta e alta qualificações.

Enfim, a simulação desse cenário mostrou que o aprofundamento da liberalização comercial pode auxiliar na ocorrência de um processo de desindustrialização no Brasil. Entretanto, a análise de bem-estar mostrou que os recursos produtivos abandonados pela indústria de transformação, entre eles o fator trabalho, seriam mais bem aproveitados em outros setores, como o setor agropecuário, de serviços e na indústria alimentícia (do próprio setor da indústria de transformação). Ou seja, a realocação do trabalho geraria aumento de bem-estar, pois melhoraria a eficiência alocativa e os termos de troca.

Os choques dos acordos preferenciais de comércio, implementados no segundo cenário, ajudam a entender qual desenho de acordos contribuiria de forma mais intensa para a desindustrialização. Nesse sentido, é com o Resto da Ásia que ocorrem as maiores distorções de mercado que protegem a indústria de transformação no Brasil. 
A eliminação de tais distorções ocasionaria uma queda na atividade desse setor, que se traduziria em queda no emprego, especialmente nas indústrias têxtil, pesada e leve. Esse emprego seria realocado para os setores agropecuário e de serviços. No setor têxtil, seria a intensificação do comércio com a China que traria maior impacto negativo no emprego. Esses trabalhadores seriam deslocados para os setores de serviços, agropecuário e indústrias extrativa e alimentícia. Em geral, o Brasil exibe competitividade em bens da indústria de transformação somente em relação ao Resto da América Latina.

Não se obtiveram resultados conclusivos quanto à desindustrialização pelo aumento de qualificação dentro da indústria de transformação. Isso se deve ao fato de que neste estudo não foram implementados choques de melhoria tecnológica dentro desse último setor. Essa questão poderá ser explorada em estudos futuros.

Apesar dos resultados preliminares alcançados com este trabalho serem importantes para a avaliação de políticas comerciais, conclusões mais consistentes carecem de maior investigação empírica com modelos mais sofisticados. No que tange à agregação dos dados, uma modificação importante seria a desagregação do setor de indústria de transformação em um maior número de produtos/setores, o que permitiria avaliar os efeitos dos choques de forma mais precisa dentro desse setor. Pelo lado da teoria, a incorporação de concorrência imperfeita e de rendimentos de escala seria um importante aspecto a ser considerado. Entretanto, para tal, é preciso que se tenham boas estimativas de margens de mark-up e extensão das economias de escala para todos os setores selecionados para a análise.

\section{REFERÊNCIAS}

BONELLI, R. Industrialização e desenvolvimento: notas e conjecturas com foco na experiência do Brasil. In: Seminário Industrialização, Desindustrialização e Desenvolvimento, FIESP e IEDI, São Paulo, 2005.

BRESSER-PEREIRA, L. C.; MARCONI, N. Existe doença holandesa no Brasil? In: Fórum de Economia de São Paulo, 4, São Paulo. Anais... São Paulo: FGV, 2008.

BURFISHER, M. E.; ROBINSON, S.; THIERFELDER, K. Regionalism: old and new, theory and practice. In: The International Agricultural Trade Research Consortium (IATRC) Conference. Capri, 2003.

COELHO, A. M.; PÁDUA LIMA, M. C.; CURY, S.; GOLDBAUM, S. Impacto de entrada da Venezuela no Mercosul: uma simulação de Equilíbrio Geral Computável. Texto para discussão, FGV/EESP, n. 153, 2006.

CENTRAL INTELLIGENCE AGENCY (CIA). South America: Brazil. In: CIA. The World Factbook. Disponível em: <https://www.cia.gov/library/publications/the-world-factbook/geos/ br.html $>$. Acesso em: 27 mai. 2015. 
FEIJÓ, C. A.; CARVALHO, P. G.; ALMEIDA, J. S. G. Ocorreu uma desindustrialização no Brasil? São Paulo: IEDI, 2005. Disponível em: <http://www.iedi.org.br/admin_ori/pdf/20051129_ desindustrializacao.pdf>. Acesso em: 14 mar. 2012.

GIOVANNETTI, B. C.; MENEZES-FILHO, N. A. “Tecnologia e a demanda por qualificação na indústria brasileira”. In: DE NEGRI, J. A. ET AL. Tecnologia, Exportação e Emprego. Brasília: IPEA, 2006.

HERTEL, T. Global Trade Analysis: modeling and applications. New York: Cambridge University Press, 1997.

LIU, J.; VAN LEEUWEN, N.; VO, T. T.; TYERS, R.; HERTEL, T. W. Disaggregating Labor Payments by Skill Level in GTAP. GTAP Technical Paper, Purdue University, n. 11, 1998.

LOPES, R. R.; CARVALHO, C. E. Acordos bilaterais de comércio como estratégia de inserção regional e internacional do Chile. Contexto Internacional, Rio de Janeiro, v. 32, n. 2, p. 643-693, 2010.

LOURES, R. R.; OREIRO, J. L.; PASSOS, C. A. K. Desindustrialização: a crônica da servidão consentida. Economia e Tecnologia, Curitiba, v. 4, 2006.

MARQUETTI, A. Progresso técnico, distribuição e crescimento na economia brasileira: 1955-1998. Estudos Econômicos, São Paulo, v. 32, n. 1, 2002.

MCDOUGALL, R. A new regional household demand system for GTAP. GTAP Technical Paper, Purdue University, n. 20, 2002. Disponível em: <https://www.gtap.agecon.purdue.edu/resources/res_display.asp?RecordID=942>. Acesso em: 01 jul. 2011.

MENEZES-FILHO, N. A.; MUENDLER, M. A. Labor Reallocation in response to trade reform. NBER Working Paper, n. 17372, 2007.

MIYAZAKI, S. O novo regionalismo econômico asiático. Contexto Internacional, Rio de Janeiro, v.27, n. 1, p. 101-125, jan./jun. 2005.

NASSIF, A. Há evidências de desindustrialização no Brasil? Economia Política, São Paulo, v. 28, n. 1 (109), 2008.

NARAYANAN, G. B.; AGUIAR, A.; MCDOUGALL, R. (Eds) Global trade, assistance, and production: The GTAP 8 Data Base., Indiana: Purdue University, Center for Global Trade Analysis, 2012. Disponível em: <https://www.gtap.agecon.purdue.edu/databases/v8/v8_ doco.asp >. Acesso em: 27 mai. 2015.

OREIRO, J. L; FEIJÓ, C. Desindustrialização: conceituação, causas, efeitos e o caso brasileiro. Economia Política, v. 30, n. 2, 2010.

PALMA, G. Quatro fontes de desindustrialização e um novo conceito de doença holandesa. In: Seminário Industrialização, Desindustrialização e Desenvolvimento, FIESP e IEDI, São Paulo, 2005.

ROWTHORN, R.; RAMASWAMY, R. Growth, trade and deindustrialization. Staff Papers, International Monetary Fund, v. 46, n.1, 1999.

SCHWARTSMAN, A. Uma tese com substâncias. Folha de São Paulo, Caderno Mercado, São Paulo, 19 ago. 2009.

SOARES, C.; MUTTER, A.; OREIRO, J. L. Uma análise empírica dos determinantes da desindustrialização no caso brasileiro (1996-2008). Departamento de Economia da UnB, Brasília, n. 361, mai. 2011. 
TREGENNA, F. Characterizing deindustrialization: an analysis of changes in manufacturing employment and output internationally. Cambridge Journal of Economics, v. 33, n. 3, p. 433-466, 2009.

WIGLE, R. The Pagan-Shannon approximation: unconditional systematic sensitivity in minutes. Empirical Economics, v. 16, p. 35-49, 1991.

WINCHESTER, N.; GREENAWAY, D.; REED, G. V. A CGE Analysis of trade and wage inequality in the UK. New Zealand: University of Otago, 2003. Disponível em: <http://www.commerce.otago.ac.nz/ECON/Personal/NW/A\%20CGE\%20Analysis\%20of\%20Trade\%20 and\%20Wage\%20Inequality.pdf>. Acesso em: 15 ago. 2011.

WOOD, A. North-South trade, employment and inequality: changing fortunes in a skill-driven world. New York: Oxford University Press, 1995. 